Research Paper:

\title{
The Effect of Education on the Knowledge of Paramedic Staff in Using Cervical Collar in Patients With Head and Neck Trauma
}

\author{
Payman Asadi $^{1}$ Q , Vahid Monsef-Kasmaei ${ }^{1}$, Seyyed-Mahdi Zia-Ziabari ${ }^{{ }^{*}}$ Q , Ehsan Kazemnejad-Leili ${ }^{1}$, Mohammad Hatef ${ }^{2}$
}

1. Guilan Road Trauma Research Center, Guilan University of Medical Sciences, Rasht, Iran

2. Department of Emergency Medicine, Poursina Hospital, Guilan University of Medical Sciences, Rasht, Iran

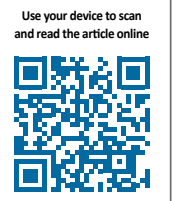

Cftation Asadi P, Monsef-Kasmaei V, Zia-Ziabari SM, Kazemnejad-Leili E, Hatef M. The Effect of Education on the Knowledge of Paramedic Staff in Using Cervical Collar in Patients With Head and Neck Trauma. Iran J Neurosurg. 2018; 4(3):149-156. http:// dx.doi.org/10.32598/irjns.4.3.149

http://dx.doi.org/10.32598/irjns.4.3.149

Article info:

Received: 17 February 2018

Accepted: 29 May 2018

Available Online: 01 July 2018

Keywords:

Education, Pre-hospital emergency, Trauma, Cervical collar

\begin{abstract}
A B S T R ACT
Background and Aim: Cervical trauma is a major injury and although using cervical collar is the standard measure in trauma patients, it is not usually applied properly. This study aimed to examine the effect of education on the knowledge of paramedic staff regarding cervical collar use in patients with head and neck injuries.

Methods and Materials/Patients: In this quasi-experimental study, 100 paramedic staff of Rasht Emergency Medical Services (EMS) participated through census sampling method. First, the knowledge of paramedics about utilizing cervical collar was examined using a researcher-made questionnaire. Then, those with low or intermediate knowledge were trained by the resident of emergency medicine. Instructional CDs, including materials on using the cervical collar were distributed among paramedics, too. After two weeks, their knowledge was tested by written and practical tests. By comparing the scores before and after the education, the effectiveness of the intervention was assessed.
\end{abstract}

Results: All samples were male. Their Mean \pm SD age and work experience were $38.8 \pm 7.5$ and $12.6 \pm 6.5$ years, respectively. The results of pre-education knowledge survey showed that the 71 (69.6\%) subjects had a moderate knowledge and 27 (26.47\%) individuals had poor knowledge, and only $4(3.9 \%)$ individuals had sufficient knowledge about using the cervical collar. Knowledge survey assessment after education in poor and moderate groups $(n=98,96.1 \%)$ showed that 73 (74.5\%) subjects had good knowledge and 25 (25.5\%) subjects had moderate knowledge. Nobody had weak knowledge.

Conclusion: The paramedic staff knowledge of using cervical collar increased after holding an appropriate educational course. Therefore, the staff with low to intermediate knowledge should be trained at least once a year.

\section{* Corresponding Author:}

Seyyed-Mahdi Zia-Ziabari, MD.

Address: Guilan Road Trauma Research Center, Guilan University of Medical Sciences, Rasht, Iran

Tel: +98 (911) 1375056

E-mail: hatef.mohammad@yahoo.com 


\section{Highlights}

- A cervical collar is not usually applied properly in trauma patients.

- Educating paramedics on the knowledge of cervical collar use in patients with head and neck injuries is necessary.

- The results of pre-education knowledge survey showed that most paramedics had moderate knowledge and less than $10 \%$ had sufficient knowledge of using the cervical collar.

\section{Plain Language Summary}

This study emphasizes that after holding educational courses for pre-hospital emergency personnel, their knowledge of using cervical collar increased. The primary goal was to study the theoretical knowledge of the paramedics in addition to their practical knowledge. We concluded that it is essential that the theoretical knowledge of this group and similar medical groups has to be re-examined, which would ultimately improve their theoretical and practical performance, and consequently, the injured patients are transferred to medical centers with better safety.

\section{Introduction}

rauma accounts for $10 \%$ of the world's T deaths [1]. Reports indicate that $2 \%$ to $4 \%$ of trauma patients have cervical spinal injuries, and $20 \%$ of them suffer from traumatic cervical spinal cord injuries, $10 \%$ show at multiple level injuries, and $10 \%$ have only ligament injury [2,3]. The cervical trauma is caused by car accident, falling, violence, quarrel, and sports injuries that can lead to death by airway obstruction and asphyxia [4].

The cervical collar is one of the most effective appliances to reduce injuries in cervical trauma. The main purpose of using a cervical collar is to immobilize the neck. Depending on the cervical collar type, the degree of the immobilization is variable [5, 6]. The cervical collars are among the important tools for pre-hospital care in patients with trauma. In fact, using the cervical collar is so important that its application is explicitly emphasized in the criteria of the $A B C$ in major trauma, along with maintaining the airway as the first step. The cervical collar plays a major role in immobilizing the potential unstable spinal cord and preventing secondary damage. Millions of trauma patients undergo cervical immobilization by wearing a collar every year [4].

It is estimated that $3 \%$ to $25 \%$ of spinal cord injuries are secondary to the injured transportation and their support [7], which can occur due to inappropriate management during pre-hospital care or at the beginning of hospital admission [8].
The potential cervical injury should be considered in all patients with driving accident-induced injuries. Therefore, preventing damage to this area through adequate protection of the neck is so vital during transporting the patients to the hospital $[9,10]$. One of the most common injuries in driving accidents is blunt neck trauma, in which the head first suddenly moves backward and then forward (whiplash injury). This type of cervical damage is not detected in X-ray imaging in 50\% of cases, while a spiral CT scan is diagnostic $[10,11]$.

Diagnosing spinal injuries in patients with trauma during the initial examination is difficult, because most patients are unconscious due to multiple injuries, or under sedative drugs or pain-killer medications. Therefore, early diagnosis of spinal injuries in the emergency departments is very important in determining diagnostic tests and timely treatment and preventing spinal cord injuries [12].

Using the appropriate type of collar and its correct application based on the scientific indications to prevent further neuromuscular damage are of high importance in patients with head and neck lesions. In most parts of the world, paramedic staff is the first health professionals to visit traumatic patients, and responsible for maintaining the stability and immobilization of the neck before transporting them to healthcare centers $[6,13,14]$. Therefore, this study was designed and conducted to assess the knowledge of paramedic staff about using the cervical collar in patients with head and neck trauma. 


\section{Methods \& Materials/Patients}

In this quasi-experimental study, all of the personnel employed in the Pre-hospital Emergency Departments in Rasht City were included. The instrument for data collection was a two-part questionnaire. The first part collected paramedics' demographic characteristics of age, work experience, and education. The second part included 15 questions about the terms and conditions for using the cervical collar. For each correct answer, a score of one was considered, and an incorrect answer did not receive any score. Finally, the score of each person was calculated by adding all obtained scores (minimum $=0$ and maximum $=15$ ). Those who gained less than $66 \%$ of the total score entered the second phase of the study, and the rest were excluded from the study.

To check the validity of this tool, a panel of experts including 10 people consisting of 7 emergency specialists, 2 neurosurgeons, and 1 anesthetist was used. The Content Validity Ratio (CVR) was examined for the necessity of the Content Validity Index (CVI) and the clarity of the questions. CVR more than $62 \%$ was obtained for each of 15 items of the questionnaire. Therefore, it had high and relevant validity according to the Lawshe Table. The $\mathrm{CVI}$ in most questions was for more than $90 \%$.

CVI for some questions was between $80 \%$ and $90 \%$, which were revised partially. The questions with the CVI between $70 \%$ and $80 \%$ were revised completely. Eventually, the validity of the tool with 15 items was confirmed after the revisions. Richardson coefficient 20 was used to determine the internal consistency of the questions for measuring the level of knowledge of the EMS unit on the use of collar in cervical spine stability. The Richardson coefficient 20 was obtained 0.72 . Therefore, the above questions had an appropriate convergence for measuring the knowledge of the personnel. The equivalent forms were used to assess the questionnaire's reliability. In this method, the sequence of questions in the equivalent form 2 was different from that in the equivalent form 1 . The test-retest reliability coefficient was 0.91 , which indicated the reliability of the tool.

Those with a low and intermediate level of knowledge (paramedics who gained less than $66 \%$ of the total score) were directly trained by the emergency medicine resident at their own base in an hourly educational session. Also, instructional CDs, including materials on how to use the cervical collar were distributed among them. After two weeks, their knowledge was measured by a written test.
By comparing the scores before and after the education, the effectiveness of the intervention was assessed.

\section{Results}

In the current study, the knowledge of 102 EMS staff of Rasht City, Iran regarding the use of cervical collar in patients with trauma was studied. All samples were male. Their Mean $\pm S D$ age and work experience were $38.8 \pm 7.5$ and $12.6 \pm 6.5$ years, respectively. A total of 41 (40.2\%) had diplomas, 18 (17.6\%) associate degree, and $43(42.2 \%)$ bachelor's degree or higher. Table 1 presents the knowledge score of the subjects in using a cervical collar before and after educational intervention based on their answers to each question.

The results of pre-education knowledge survey showed that the majority of the study participants, i.e. $71(69.6 \%)$ individuals had moderate knowledge (score between $33.3 \%$ and $66.6 \%), 27$ (26.47\%) had low knowledge (score less than $33.3 \%$ ), and only $4(3.9 \%)$ had sufficient knowledge (score more than 66.6\%) regarding the use of cervical collar. The Pearson correlation coefficient showed no statistically significant relationship between the level of knowledge of personnel with their age, work experience, and education ( $P>0.05)$.

After education, knowledge survey on the two weak and moderate groups $(n=98,96.1 \%)$ showed that 73 (74.5\%) individuals had a good level of knowledge and $25(25.5 \%)$ individuals had a moderate level. None of the samples had weak knowledge (Table 2). Comparison of the scores before and after the education showed that the Mean $\pm S D$ scores of knowledge after education improved (7.67 \pm 2.1 vs. $14.52 \pm 1.68)$. Changes in the score $(6.85 \pm 1.97)$ were statistically significant based on the paired t-test (Table 3).

\section{Discussion}

Most pre-hospital emergency systems around the world use cervical collars for patients with significant injuries [15]. In order to prevent secondary damages, spinal immobilization is performed by the cervical collars as the main care in trauma patients in the past few decades [16]. Since very little evidence was found on the assessment of the knowledge of emergency medical personnel in Guilan Province, this study was conducted to determine the knowledge level of medical emergency personnel in Rasht City, regarding using the cervical collar for traumatic patients. 
Table 1. Pre-hospital emergency department staff knowledge on using cervical collar in traumatic patients before and after education

\begin{tabular}{|c|c|c|c|c|c|c|c|c|c|c|c|c|c|}
\hline \multirow{3}{*}{ No. } & \multirow{3}{*}{ Question } & \multicolumn{6}{|c|}{ Before Education } & \multicolumn{6}{|c|}{ After Education } \\
\hline & & \multicolumn{2}{|c|}{ Incorrect } & \multicolumn{2}{|c|}{ Correct } & \multicolumn{2}{|c|}{ Total } & \multicolumn{2}{|c|}{ Incorrect } & \multicolumn{2}{|c|}{ Correct } & \multicolumn{2}{|c|}{ Total } \\
\hline & & No. & $\%$ & No. & $\%$ & No. & $\%$ & No. & $\%$ & No. & $\%$ & No. & $\%$ \\
\hline 1 & $\begin{array}{l}\text { The most common cause of cervical } \\
\text { injury }\end{array}$ & 65 & 63.7 & 37 & 36.3 & 102 & 100 & 26 & 26.5 & 72 & 73.5 & 98 & 100 \\
\hline 2 & $\begin{array}{l}\text { The best tool used along with the col- } \\
\text { lar for cervical spine immobilization }\end{array}$ & 48 & 47.1 & 54 & 52.9 & 102 & 100 & 0 & 0.0 & 98 & 100.0 & 98 & 100 \\
\hline 3 & $\begin{array}{l}\text { The most common type of cervical } \\
\text { spine injury mechanism }\end{array}$ & 80 & 78.4 & 22 & 21.6 & 102 & 100 & 46 & 46.9 & 52 & 53.1 & 98 & 100 \\
\hline 4 & $\begin{array}{c}\text { Conditions requiring cervical collar } \\
\text { attachment }\end{array}$ & 58 & 56.9 & 44 & 43.1 & 102 & 100 & 1 & 1.0 & 97 & 99.0 & 98 & 100 \\
\hline 5 & $\begin{array}{l}\text { The highest prevalence of cervical } \\
\text { injuries in the vertebrae }\end{array}$ & 76 & 74.5 & 26 & 25.5 & 102 & 100 & 54 & 55.1 & 44 & 44.9 & 98 & 100 \\
\hline 6 & $\begin{array}{l}\text { The predictors of severity of cervical } \\
\text { and spinal cord injury }\end{array}$ & 92 & 90.2 & 10 & 9.8 & 102 & 100 & 77 & 78.6 & 21 & 21.4 & 98 & 100 \\
\hline 7 & Way of attaching cervical collar & 37 & 36.3 & 65 & 63.7 & 102 & 100 & 2 & 2.0 & 96 & 98.0 & 98 & 100 \\
\hline 8 & $\begin{array}{l}\text { Dealing with an injured patient meet- } \\
\text { ing cervical collar attachment criteria }\end{array}$ & 28 & 27.5 & 74 & 72.5 & 102 & 100 & 2 & 2.0 & 96 & 98.0 & 98 & 100 \\
\hline 9 & $\begin{array}{c}\text { The best type of collar in traumatic } \\
\text { cervical injury }\end{array}$ & 62 & 60.8 & 40 & 39.2 & 102 & 100 & 5 & 5.1 & 93 & 94.9 & 98 & 100 \\
\hline 10 & $\begin{array}{l}\text { The most important way to reduce } \\
\text { cervical injuries }\end{array}$ & 92 & 90.2 & 10 & 9.8 & 102 & 100 & 10 & 10.2 & 88 & 89.8 & 98 & 100 \\
\hline 11 & $\begin{array}{l}\text { Procedure of using the cervical collar } \\
\text { in the traumatic patient }\end{array}$ & 68 & 66.7 & 34 & 33.3 & 102 & 100 & 9 & 9.2 & 89 & 90.8 & 98 & 100 \\
\hline 12 & $\begin{array}{l}\text { Maximum permitted wearing time for } \\
\text { cervical collar in patients with trauma }\end{array}$ & 87 & 85.3 & 15 & 14.7 & 102 & 100 & 60 & 61.2 & 38 & 38.8 & 98 & 100 \\
\hline 13 & $\begin{array}{l}\text { Person examining cervical injuries in } \\
\text { patient with trauma }\end{array}$ & 63 & 61.8 & 39 & 38.2 & 102 & 100 & 48 & 49.0 & 50 & 51.0 & 98 & 100 \\
\hline 14 & $\begin{array}{l}\text { Lack of meeting criteria for cervical } \\
\text { injuries }\end{array}$ & 15 & 14.7 & 87 & 85.3 & 102 & 100 & 5 & 5.1 & 93 & 94.9 & 98 & 100 \\
\hline 15 & $\begin{array}{l}\text { Patient's condition to attach cervical } \\
\text { collar }\end{array}$ & 7 & 6.9 & 95 & 93.1 & 102 & 100 & 2 & 2.0 & 96 & 98.0 & 98 & 100 \\
\hline
\end{tabular}

In our study, all paramedics were male with a Mean \pm SD age of $38.8 \pm 7.5$ years. Most of them had bachelor's degree with a Mean $\pm S D$ work experience of $12.6 \pm 6.5$ years.
The primary results before education showed that only $3.9 \%$ of the subjects had a good knowledge level, and

Table 2. Pre-hospital emergency personnel knowledge status before and after education on using the cervical collar in patients with trauma

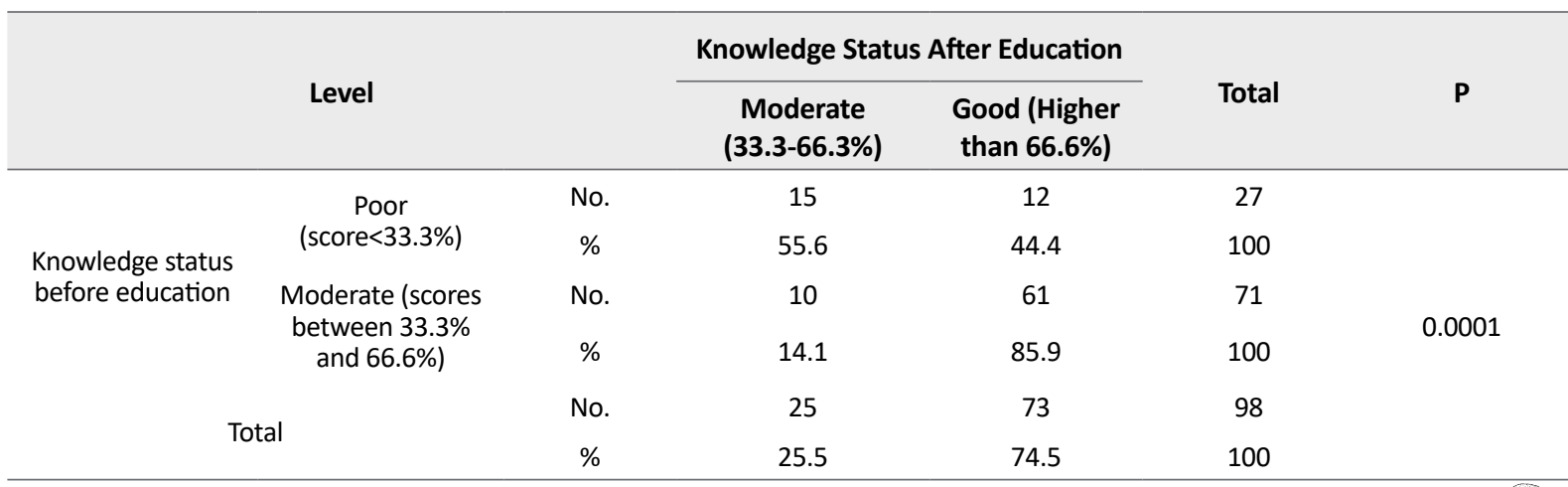


Table 3. Comparison of knowledge score before and after pre-hospital emergency personnel education on using cervical collar in patients with trauma

\begin{tabular}{|c|c|c|c|c|c|}
\hline Variable & No. & Mean士SD & Median & 95\% Cl Lower Bound & $\begin{array}{l}\text { 95\% Cl Upper } \\
\text { Bound }\end{array}$ \\
\hline $\begin{array}{l}\text { Paramedics knowledge before } \\
\text { education }\end{array}$ & 98 & $7.67 \pm 2.12$ & 8.00 & 7.25 & 8.10 \\
\hline $\begin{array}{c}\text { Paramedics knowledge after } \\
\text { education }\end{array}$ & 98 & $14.52 \pm 1.68$ & 15.00 & 14.18 & 14.86 \\
\hline $\begin{array}{c}\text { Paramedics Knowledge changes } \\
\text { before and after Education }\end{array}$ & 98 & $6.85 \pm 1.97$ & 7.00 & 6.45 & 7.24 \\
\hline $\begin{array}{l}\text { Paramedics knowledge percent- } \\
\text { age changes before and after } \\
\text { Education }\end{array}$ & 98 & $104.60 \pm 62.64$ & 86.61 & 92.04 & 117.16 \\
\hline$P$ & \multicolumn{5}{|c|}{0.0001} \\
\hline
\end{tabular}

most of them had moderate to weak knowledge regardless of their age, education, and experiences.

Ziabari et al. studied on the knowledge and practice of medical staff about cervical collar in traumatic patients. Their results were consistent with our study results. They studied 80 medical staff with a Mean \pm SD age of $25.93 \pm 1.02$ years, of which $72.2 \%$ were women. Mean $\pm S D$ score of knowledge and practice of the participants was $11.5 \pm 2.7$ and $16.5 \pm 2.3$ years, respectively.

The worst lack of theoretical knowledge comprised predictor factors of the spinal cord and cervical injuries $(98.8 \%)$, the importance of injury $(95 \%)$, the maximum permitted the length of use of cervical collar (91.3\%), and inappropriate measures (91.3\%). Also, the worst lack of practical knowledge was related to leveling external auditory meatus with shoulder after attaching the cervical collar in children $(98.8 \%)$, placing a protective pad behind the chest after attaching the cervical collar in children (95\%), and employing at least three individuals when attaching cervical collar, and spinal column immobilization before attaching cervical collar (65\%). The findings of the study indicated that the level of knowledge and practice about using cervical collar were intermediate to poor in more than $70 \%$ and $60 \%$ of paramedics, respectively [14].

In the study of Kreinest et al. the Mean \pm SD age of the participants was $34.5 \pm 10.3$ years. The majority of the personnel were rescue workers (80.8\%) and emergency medicine doctors (12.5\%). Their Mean \pm SD working experience was $11.1 \pm 8.9$ years. About $11 \%$ of them attached the cervical collar correctly on a medical moulage. The most common mistake (66\%) was related to the incorrect adjustment of the cervical collar size [6].
The low level of knowledge can result in serious complications for the patient's life, since about 3\% to $25 \%$ of the cases of spinal cord injuries are secondary and happen due to inappropriate management, such as the lack of immobilization in the spinal cord during pre-hospital or hospital care. Spinal cord injury leading to permanent damage in the cervical area is a potential threat to the traumatic patient's life. It is also one of the causes where negligence on the part of the emergency staff and the occurrence of a complication has a legal burden.

Using a cervical collar in the pre-hospital phase reflects the high quality of care for patients with trauma. Using the cervical collar is recommended in many guidelines such as Advanced Trauma Life Support (ATLS) and Prehospital Trauma Life Support (PHTLS). In many protocols, pre-hospital emergency staff cannot transfer trauma patients to the hospital emergency unit without attaching the cervical collar [4]. Therefore, given to the low level of personnel knowledge and the importance of using a cervical collar, the need for educational intervention is justified. Statistical analyses of the present study showed no significant relationship between the level of knowledge of personnel with their work experience and their education, which is consistent with the results of Kreinest et al. study [6]

Analysis of post-education data indicated that proper education had a positive impact on improving the level of knowledge about how to use the cervical collar so that most paramedics had gained good knowledge. Therefore, the emergency personnel, especially the pre-hospital emergency staff, should continue and refresh their knowledge regarding the use of the cervical collar. It is also necessary to include continuing education credits on spinal immobilization in the current curriculum [13]. In many other studies, the impact of the 
education and subsequent enhancement of individuals' knowledge have been proven $[17,18]$.

This study had some limitations. Firstly, few demographic factors were studied. We avoided extending the questionnaire due to lack of time for pre-hospital emergency personnel to fill in the questionnaire and having a high number of respondents. Secondly, most of our study participants had a bachelor's degree or higher, but a lot of paramedics had a diploma. Given that they do not have a proper academic knowledge of cervical and spinal cord injuries, health policy makers need to hire trained and specialized staff, especially in the prehospital care settings, and improve primary care quantitatively and qualitatively.

Strong points of our study were as follows: This research assessed the knowledge of personnel regarding the cervical collar for the first time. In the reports and other similar studies, the method of attaching the cervical collar and its practical use were mainly focused on the use of cervical collar in triage patients, while in the present study the level of knowledge of personnel about using cervical collar, as well as the importance and impact of education on the level of knowledge of personnel were evaluated. Next, the education was provided by an emergency medicine resident lecturing at each base along with giving the educational CD-ROM. Using the multimedia educational package can have a more lasting impact compared to giving lectures $[19,20]$.

Currently, some reports indicate the contradictory results in using the cervical collar. It has been proved that the disadvantages of using cervical collar are more than its benefits, so we can simply stop using it. Complications such as a significant increase in intracranial pressure and cerebral edema development $[10,11]$, reduced ability to open the patient's mouth, which in turn could endanger airway management, as well as the deterioration of the neurological symptoms of patients with chest trauma, who used the cervical collar, have been observed [5, 21, 22]. Therefore, pre-hospital emergency staff should be able to identify and manage the proper protocol for using the cervical collar for patients with trauma. These patients should not only be fixed with a single cervical collar but also should be immobilized on the spinal board with blocks and belts [4].

Since the impact of education is significant, it is sug gested that pre-hospital emergency staff be provided with continuing education courses for the training of various emergency procedures. It is also recommended that larger sample size be used to evaluate the perfor- mance of emergency staff in order to care for patients with trauma in future studies.

\section{Conclusion}

Our study indicates that after holding educational courses for pre-hospital emergency personnel, their knowledge on using cervical collar increased and $74.5 \%$ of the personnel had gained a good level at the knowledge. Therefore, the results show that education on using cervical collar is so vital. Our study showed that pre-hospital emergency staff knowledge on the use of cervical collar increased after holding training courses for them, and it turned good in $74.5 \%$ of the staff. Therefore, the education on using cervical collar is crucial, and the increase in knowledge on using the cervical collar and similar training play a significant role in improving the performance of EMS personnel before transporting the injured patients to the hospitals.

\section{Ethical Considerations}

\section{Compliance with ethical guidelines}

There was no ethical considerations to be considered in this research.

\section{Funding}

This research did not receive any specific grant from funding agencies in the public, commercial, or not-forprofit sectors.

\section{Authors' contributions}

Conception and design: Payman Asadi; Data collection: Mohammad Hatef; Drafting the article: Mohammad Hatef; Critically revising the article: All authors; Reviewing submitted version of manuscript: All authors; and Approved the final version of the manuscript: All authors.

\section{Conflict of interest}

The authors declared no conflict of interest.

\section{References}

[1] Hasler RM, Exadaktylos AK, Bouamra O, Benneker LM, Clancy M, Sieber R, et al. Epidemiology and predictors of cervical spine injury in adult major trauma patients: A multicenter cohort study. The Journal of Trauma and Acute Care Sur- 
gery. 2012; 72(4):975-81. [DOI:10.1097/TA.0b013e31823f5e8e] [PMID]

[2] Chiu WC, Haan JM, Cushing BM, Kramer ME, Scalea TM. Ligamentous injuries of the cervical spine in unreliable blunt trauma patients: Incidence, evaluation, and outcome. The Journal of Trauma and Acute Care Surgery. 2001; 50(3):45764. [DOI:10.1097/00005373-200103000-00009]

[3] Demetriades D, Charalambides K, Chahwan S, Hanpeter D, Alo K, Velmahos G, et al. Nonskeletal cervical spine injuries: epidemiology and diagnostic pitfalls. The Journal of Trauma and Acute Care Surgery. 2000; 48(4):724-7. [DOI:10.1097/00005373-200004000-00022]

[4] Sundstrøm T, Asbjørnsen H, Habiba S, Sunde GA, Wester K. Pre-hospital use of cervical collars in trauma patients: A critical review. Journal of Neurotrauma. 2014; 31(6):531-40. [DOI:10.1089/neu.2013.3094] [PMID] [PMCID]

[5] Goutcher C, Lochhead V. Reduction in mouth opening with semi-rigid cervical collars. British Journal of Anaesthesia. 2005; 95(3):344-8. [DOI:10.1093/bja/aei190] [PMID]

[6] Kreinest M, Goller S, Rauch G, Frank C, Gliwitzky B, Wölfl CG, et al. Application of cervical collars: An analysis of practical skills of professional emergency medical care providers. PloS One. 2015; 10(11):e0143409. [DOI:10.1371/journal. pone.0143409] [PMID] [PMCID]

[7] Theodore N, Hadley MN, Aarabi B, Dhall SS, Gelb DE, Hurlbert RJ, et al. Pre-hospital cervical spinal immobilization after trauma. Neurosurgery. 2013; 72(3):22-34. [DOI: 10.1227/ NEU.0b013e318276edb1]

[8] Marshall LF, Knowlton S, Garfin SR, Klauber MR, Eisenberg HM, Kopaniky D, et al. Deterioration following spinal cord injury: a multicenter study. Journal of Neurosurgery. 1987; 66(3):400-4. [DOI:10.3171/jns.1987.66.3.0400] [PMID]

[9] Ben-Galim P, Dreiangel N, Mattox KL, Reitman CA, Kalantar SB, Hipp JA. Extrication collars can result in abnormal separation between vertebrae in the presence of a dissociative injury. The Journal of Trauma and Acute Care Surgery. 2010; 69(2):447-50. [DOI:10.1097/TA.0b013e3181be785a] [PMID]

[10] Mobbs RJ, Stoodley MA, Fuller J. Effect of cervical hard collar on intracranial pressure after head injury. ANZ Journal of Surgery. 2002; 72(6):389-91. [DOI:10.1046/j.14452197.2002.02462.x]

[11] Lemyze M, Palud A, Favory R, Mathieu D. Unintentional strangulation by a cervical collar after attempted suicide by hanging. Emergency Medicine Journal. 2011; 28(6):532. [DOI:10.1136/emj.2010.106625] [PMID]

[12] Hasler RM, Exadaktylos AK, Bouamra O, Benneker LM, Clancy M, Sieber R, et al. Epidemiology and predictors of spinal injury in adult major trauma patients: European cohort study. European Spine Journal. 2011; 20(12):2174-80. [DOI:10.1007/s00586-011-1866-7] [PMID] [PMCID]

[13] Bouland AJ, Jenkins JL, Levy MJ. Assessing attitudes toward spinal immobilization. The Journal of Emergency Medicine. 2013; 45(4):e117-e25. [DOI:10.1016/j.jemermed.2013.03.046] [PMID]

[14] Ziabari SMZ, Kasmaei VM, Pourshafiei SH, Saadatmand $\mathrm{S}$. Knowledge and practice of medical interns regarding use of neck collar in trauma patients: A cross-sectional study. Iranian Journal of Emergency Medicine. 2018; 5:11.
[15] Deasy C, Cameron P. Routine application of cervical collars-What is the evidence. Injury. 2011; 42(9):841-2. [DOI:10.1016/j.injury.2011.06.191] [PMID]

[16] Stanton D, Hardcastle T, Muhlbauer D, Van Zyl D. Cervical collars and immobilisation: A South African best practice recommendation. African Journal of Emergency Medicine. 2017; 7(1):4-8. [DOI:10.1016/j.afjem.2017.01.007] [PMID] [PMCID]

[17] Haghdoost Z, Safari M, Yahyavi H. [Effect of triage education on knowledge, attitude and practice of nurses in Poursina Educational and Therapeutic Emergency Center in Rasht (Persian)]. Journal of Holistic Nursing and Midwifery. 2010; 20(2):14-21.

[18] Ebrahimi S, Ghofranipour F, Tavousi M. The effect of educational intervention on promoting healthy eating behaviors among primary school students in Kermanshah City, Iran Journal of Epidemiology and Community Health. 2016; 3(3):17-23. [DOI:10.21859/jech-03033]

[19] Sadat L, Foruzesh R, Mahmoodi Z, Tahamtani T, Beirami A, Farmani P. [Comparison of the effect of two teaching methods on nurses' awareness of occupational hazards and safety measures: Lectures versus educational packages (Persian)] Journal of Advances in Modeling Earth Systems. 2015; 1(1):1-9.

[20] Hugenholtz NI, De Croon EM, Smits PB, Van Dijk FJ, Nieuwenhuijsen K. Effectiveness of e-learning in continuing medical education for occupational physicians. Occupational Medicine. 2008; 58(5):370-2. [DOI:10.1093/occmed/kqn053] [PMID] [PMCID]

[21] Clarke A, James S, Ahuja S. Ankylosing spondylitis: Inadvertent application of a rigid collar after cervical fracture, leading to neurological complications and death. Acta Orthopaedica Belgica. 2010; 76(3):413-5. [PMID]

[22] Papadopoulos MC, Chakraborty A, Waldron G, Bell BA. Lesson of the week: Exacerbating cervical spine injury by applying a hard collar. BMJ: British Medical Journal. 1999; 319(7203):1712. [DOI:10.1136/bmj.319.7203.171] [PMID] [PMCID] 
This Page Intentionally Left Blank 